\title{
DIREITOS HUMANOS: DA UNIFORMIDADE DA ESPÉCIE À UNIVERSALIDADE DO DIREITO
}

\author{
Moisés Rodrigues da Silva ${ }^{1}$ \\ Universidade Federal de Goiás (UFG) \\ Instituto Federal de Goiás (IFG) \\ https://orcid.org/0000-0002-5590-3659
}

RESUMO:

Este artigo pretende abordar, por um viés filosófico, o problema dos Direitos Humanos enunciados em Declarações dos séculos XVIII e XX. A questão de fundo consiste nos Direitos do Homem a partir do "ideal de humanidade" ou "dignidade humana" considerando duas ideias: 1) o paradoxo da Declaração dos Direitos do Homem e do Cidadão e a noção de que só se sente um "humano" com direitos garantidos alguém que se vê contemplado no bojo jurídico de uma nação. 2) A humanidade como "grande família" (Declaração Universal dos Direitos Humanos, de 1948), e o mundo como "grande nação". Para tanto, promovemos neste trabalho um debate entre três pensadores: Diderot, com sua noção de vontade geral do gênero humano; Rousseau, com sua refutação à tese de Diderot, negando que exista uma "sociedade natural ou geral entre os homens"; e Kant, que no seu $\dot{A}$ Paz Perpétua retoma, a seu modo, a noção de cosmopolitismo negada por Rousseau e aponta para a possibilidade do direito se estender a toda a humanidade.

PALAVRAS-CHAVE: Homem; Direito; Uniformidade; Universalidade.

\section{HUMAN RIGHTS: FROM THE UNIFORMITY OF THE SPECIES TO THE UNIVERSALITY OF THE RIGHT}

\begin{abstract}
:
This article intends to approach, for a philosophical bias, the problem of Human Rights enunciated in Declarations of the XVIII and XX centuries. The basic question is human rights based on the "ideal of humanity" or "human dignity", considering two ideas: 1) the paradox of the Declaration of the Rights of Man and of the Citizen and the notion that one feels only a human "With guaranteed rights someone who sees himself contemplated in the legal scope of a nation. 2) Humanity as a "great family" (Universal Declaration of Human Rights, 1948), and the world as "great nation". Therefore, we promote in this work a debate between three thinkers: Diderot, with his notion of the general will of the human race; Rousseau, with his refutation of Diderot's thesis, denying that there is a "natural or general society among men"; And Kant, who in his Perpetual Peace, in his own way, takes up the notion of cosmopolitanism denied by Rousseau and points to the possibility of the right to extend to all mankind.
\end{abstract}

KEYWORDS: Man; Right; Uniformity; Universality.

\footnotetext{
${ }^{1}$ Doutorando em Filosofia pela Universidade Federal de Goiás (UFG), Goiás - Brasil e professor do no Instituto Federal de Goiás - Campus Itumbiara (IFG), Goias - Brasil. E-mail: professormoisesrodrigues@hotmail.com
}

SILVA, Moisés Rodrigues da. Dreitos humanos: da uniformidade da espécie à universalidade do direito. Griot : Revista de Filosofia, Amargosa, Bahia, v.16, n.2, p.132-147, dezembro/2017. 
Há muito tempo - mais especificamente desde Sócrates e os sofistas -, o homem é um dos objetos prediletos da filosofia. Mas, apenas há alguns séculos, principalmente a partir da modernidade, os pensadores se depararam com a necessidade de abordarem, para além dos deveres, das regras e costumes que a tradição (religiosa ou não) impunha aos homens, certos direitos que estes supostamente possuem justamente por serem homens. Jusnaturalistas e juspositivistas, iluministas e os críticos destes, todos contribuíram de alguma forma para o pensamento acerca dos direitos do homem à medida que lutavam contra as funestas consequências dos abusos tanto do poder político como do poder econômico. Sem nos arriscarmos a eleger datas para o surgimento dessa preocupação com os direitos humanos - o que certamente nos remeteria a tempos bem longínquos -, podemos ao menos intuir que a Renascença, a Imprensa, a Reforma Protestante e a Contrarreforma, além da Revolução Científica, aceleraram um processo que culminou nas revoluções Gloriosa, Francesa e Industrial (entre outras), bem como em emblemáticas declarações de direitos, como a Declaração da Independência dos Estados Unidos da América, de 1776, a Declaração dos Direitos do Homem e do Cidadão, na França em 1789 e, por fim, na Declaração Universal dos Direitos Humanos, pela ONU em $1948 .^{2}$

No entanto, apesar de tantos avanços no que diz respeito à concepção, à reivindicação e mesmo ao reconhecimento dos direitos do homem, o assunto parece intrincado numa série de problemas. Nosso trabalho visa tratar, sob uma perspectiva filosófica, um desses problemas em especial. Queremos analisar, mesmo que brevemente, a possibilidade de se pensar os direitos do homem a partir da admissão ou não de certa unidade (ou uniformidade) da espécie humana que poderia se evidenciar no ideal de "humanidade" ou de "dignidade humana". Afinal, a Terra inteira está habitada por seres humanos, e estes, malgrado tantas diferenças, são todos pelo menos igualmente humanos.

A dificuldade, porém, se manifesta por meio da consideração de dois aspectos conflitantes tanto das Declarações do século $\mathrm{XVIII}^{3}$ como de sua fundamentação filosófica. Por um lado, as Declarações e as principais teorias políticas da modernidade pretendem que os homens sejam dotados de direitos inerentes. Na Declaração da Independência dos EUA, de 1776, se diz que "todos os homens são criados iguais, dotados pelo seu Criador de certos Direitos inalienáveis" (HUNT, 2009, p. 219) ${ }^{4}$, enquanto a Declaração dos Direitos do Homem e do Cidadão, de 1789, afirma solenemente "os direitos naturais, inalienáveis e sagrados do homem" (HUNT, 2009 , p. 225) ${ }^{5}$. No plano filosófico, os maiores expoentes desse aspecto universalista são os contratualistas, como Hobbes, Locke e Rousseau, para os quais os homens são, por exemplo, todos iguais por natureza. ${ }^{6}$ Por outro lado, contudo, as mesmas

\footnotetext{
2 As versões das três Declarações que utilizo aqui estão anexadas ao texto de Lynn Hunt, $A$ invenção dos direitos humanos: uma história. São Paulo: Cia das Letras, 2009.

${ }^{3} \mathrm{O}$ motivo para excetuarmos a Declaração de 1948 ficará claro mais à frente no trabalho, justamente porque apresenta um progresso diante da dificuldade que se apresenta aqui.

${ }^{4}$ Grifo nosso.

${ }^{5}$ Grifo nosso.

6 “A Natureza fez os homens tão iguais quanto às faculdades do corpo e do espírito..." (HOBBES, 1997, p. 107); “nada havendo de mais evidente que criaturas da mesma espécie e da mesma ordem, nascidas promiscuamente a todas as mesmas vantagens da natureza e ao uso das mesmas faculdades,
} 
fontes apontam para um fator que parece se impor e abalar o caráter universal da humanidade. Nos mesmos textos que defendem a igualdade de "todos os homens", surgirá, como condição de possibilidade de garantia de direitos, justamente a nacionalização (a particularização, a segregação), de forma que o Estado, a política e a positivação jurídica se mostram indispensáveis para o reconhecimento dos chamados direitos do homem. ${ }^{7}$ Na Declaração de 1776 , por exemplo, logo após aquele preâmbulo tão universalista, o congresso estadunidense (consequentemente por se tratar de uma declaração de independência) segue com uma série de particularizações, acentuando a vinculação necessária da efetivação daqueles direitos a um governo justo que possa e queira assegurá-los (HUNT, 2009, p. 219). A primeira frase da Declaração de 1789 já denuncia sua carga particularista: "Os representantes do povo francês, reunidos em Assembleia Nacional, [...] resolveram..." (HUNT, 2009, p. 225) ${ }^{8}$. Além disso, no mesmo espírito da declaração americana, a francesa assevera adiante que "o objetivo de toda associação política é a preservação dos direitos naturais e imprescindíveis do homem" (HUNT, 2009, p. $226)^{9}$. No que tange ao âmbito do pensamento, aqueles três filósofos, exatamente por serem contratualistas, vão elaborar, cada um a seu modo, um conjunto de ideias que visem justificar a existência do Estado, mostrando que, pelo menos uma parcela da humanidade (aquela que faz o pacto fundante do Estado) terá seus direitos efetivamente resguardados. ${ }^{10}$

Entretanto, para além desse paradoxo que se percebe na difícil equação das Declarações dos Direitos do Homem do século XVIII e a noção de que só se sente um "humano" com direitos garantidos alguém que se vê abrigado no bojo jurídico de uma nação, pretendemos levar em consideração uma ideia bastante interessante que encontrará lugar notadamente nos séculos seguintes, a saber: a humanidade como

terão também de ser iguais umas às outras sem subordinação ou sujeição" (LOCKE, 1978, p. 35); já em Rousseau, os homens são, por natureza, igualmente livres e perfectíveis (ROUSSEAU, 1999, pp. 64 e 65$)$.

7 Embora a existência do aparato estatal não signifique necessariamente a efetivação de direitos, podendo mesmo ser fator de esvaziamento destes, justamente porque esse aparato pode retirar direitos dos "outros" ao especificar quem é o sujeito de direito, como aconteceu na Alemanha dos anos 1930. Além disso, o forte e extenso aparelho de Estado em ditaduras significa frequentemente o aniquilamento de direitos civis e sociais dos particulares e minorias.

${ }^{8}$ Grifo nosso.

${ }^{9}$ Grifo nosso.

${ }^{10}$ Em Hobbes, os homens, apesar de viverem em estado permanente de guerra entre si, são suscetíveis a paixões que os fazem "tender para a paz" e à razão que "sugere adequadas normas de paz, em torno das quais os homens podem chegar a acordo" (HOBBES, 1997, p. 111). Todos, igualmente, querem se conservar, mas o estado de guerra dificulta sobremaneira a realização desse desejo. $O$ Estado surgirá, portanto, para dar conta desse problema (pelo menos para os que se submeterem a ele) (HOBBES, 1997, p. 144). Em Locke, mesmo que o estado natural dê provas de certa racionalidade e harmonia, seus inconvenientes exigem a criação do Estado para assegurar aos homens a posse de sua vida, sua liberdade e seus bens (LOCKE, 1978, pp. 38, 39 e 84). Também em Rousseau, características compartilhadas por toda a humanidade, como o instinto de autoconservação e a liberdade, permanecem ameaçadas enquanto estiverem dependentes apenas da força dos indivíduos. Por isso, é preciso "Encontrar uma forma de associação que defenda e proteja a pessoa e os bens de cada associado [e não de todo ser humano] com toda a força comum, e pela qual cada um, unindo-se a todos, só obedece contudo a si mesmo, permanecendo assim tão livre quanto antes" (ROUSSEAU, 2000 , pp. 69 e 70$)$. 
grande "família", como se lê na Declaração Universal dos Direitos Humanos (HUNT, 2009 , p. 229) e o mundo como uma "grande nação", uma "grande Pólis", por assim dizer. Será que a noção de que o planeta inteiro possa ser regido por leis comuns pode apontar para um progresso com relação aos direitos de seus habitantes? Já que nem mesmo estes primeiros grandes esforços de formulação dos direitos do homem conseguem resolver por si mesmos a contradição de direitos que, por um lado, incluem todos os homens, mas que, por outro, se efetivam apenas dentro de um aparato artificial - que, por definição, é excludente ${ }^{11}$-, então um caminho possível seria conjeturar um construto político capaz (como os direitos) de incluir todos os homens, um aparato artificial que não fosse apenas Pólis, mas "Cosmopólis". Nesse sentido, a Declaração Universal, de 1948, e a tese de Kant contida especialmente em seu À Paz Perpétua denotam um avanço extraordinário.

Antes de Kant, no mesmo século XVIII, houve um autor que já havia esboçado a ideia de que o gênero humano seja uma entidade moral única, dotada de uma vontade que nunca se engana e busca sempre o bem de todos os seus membros. Não nos referimos aqui ao Abade de Saint-Pierre, que escreveu um extenso Projeto Para Tornar Perpétua a Paz na Europa, ${ }^{12}$ e sim a Diderot com seu breve verbete na Encyclopédie intitulado Direito Natural. Certamente será sobremodo proveitoso para nossa discussão fazermos um recuo a Diderot e principalmente a uma crítica a seu texto elaborada por Rousseau no Capítulo II da primeira versão do Contrato Social, comumente conhecida como Manuscrito de Genebra.

Diderot sugere, ainda que superficialmente, uma unidade do gênero humano não apenas em seu aspecto físico, mas principalmente moral, ligando o "direito natural" à vontade geral da espécie humana pautada em sua faculdade exclusiva, a razão. $O$ gênero humano constituiria assim, de certo modo, uma sociedade de todos os homens regida pelo direito natural. De forma didática, para compreender em que consiste o direito, o filósofo introduz um personagem a quem dá a alcunha de "o raciocinador violento", "homem injusto e dominado por paixões [e que] sente-se levado a fazer a outro o que não gostaria que lhe fizessem" (DIDEROT, 2006, p. 78). $\mathrm{O}$ direito pressupõe o homem livre para que ele possa ser justo, mas por isso mesmo ele age com injustiça e se alija da dignidade humana - que, segundo o autor, é constituída por "uma ordem de ideias e de conhecimentos particulares à espécie humana" (DIDEROT, 2006, p. 80) -, tornando-se, com relação ao resto da espécie, um "animal feroz" (DIDEROT, 2006, p. 79), pois "aquele que não quer raciocinar, renunciando assim à sua qualidade de homem, deve ser tratado como um ser desnaturado" (DIDEROT, 2006, p. 82).

Como trazer de volta ao direito esse raciocinador violento, tão imbuído de sua injusta vontade particular? Diderot questiona também:

se tiramos do indivíduo o direito de decidir sobre a natureza do justo e do injusto, onde apresentaremos esta grande causa? Onde? Diante do gênero

\footnotetext{
11 Pois, em geral, a nacionalidade de um homem soma como uma das características distintivas dele com relação aos outros.

12 Referindo-se a esse livro, Rousseau diz que "Nunca a mente humana concebeu um esquema mais nobre, mais belo ou útil do que o de uma paz perpétua e universal entre todos os povos da Europa, e nunca um escritor mereceu mais respeito do que quem sugeriu os meios de pôr em prática esse esquema" (ROUSSEAU, 2003, p. 71).
} 
humano; é a ele que cabe decidi-la, porque o bem de todos é a sua única paixão. As vontades particulares são suspeitas; elas podem ser boas ou más, mas a vontade geral é sempre boa, nunca se engana, nunca se enganará (DIDEROT, 2006, p. 80).

O indivíduo, então, para conseguir conformar-se à humanidade, deve dirigir-se à vontade geral do gênero humano, que é, de acordo com o filósofo, "em cada indivíduo um ato puro do entendimento que raciocina no silêncio das paixões sobre aquilo que seu semelhante tem direito de exigir" (DIDEROT, 2006, p. 81).

A tese diderotiana impacta Rousseau de tal maneira que este dedicará, no Manuscrito de Genebra, um capítulo inteiro para debatê-la. O capítulo II desta obra é uma clara resposta ao texto de Diderot; é uma refutação aberta (embora sem referência explícita), contendo trechos inteiros do verbete. ${ }^{13}$

Certamente, diz Rousseau, a expressão espécie humana (le mot de genre humain) sugere apenas uma ideia puramente coletiva que não implica a união real dos indivíduos que a constituem. Acrescente-se a isso, se o quisermos, essa suposição, para conceber a espécie humana como uma personalidade moral (personne morale) sujeita à motivação universal que faz com que cada parte atue tendo em vista uma meta que é geral e se relaciona com o conjunto (juntamente com o sentimento da existência comum que lhe dá individualidade e a representa como uma unidade). Imaginemos que esse laço comum seja o sentimento humanitário (sentiment de l'humanité), e que o direito natural seja o princípio ativo de todo o mecanismo em questão. (ROUSSEAU, 2003, p. 116)

Depois de apresentar essa "suposição", que parece mais ser um resumo do exposto pelo filósofo francês em seu verbete, o autor genebrino apressa-se a adicionar:

Observemos em seguida o que resulta da constituição do homem nas suas relações com os outros homens; contrariando completamente o que tínhamos suposto, veremos que ao despertar-lhes o interesse pessoal, o desenvolvimento da sociedade sufoca o sentimento humanitário (l'humanité) no seu coração; e que os conceitos da lei natural, que na verdade deveria ser conhecida como a lei da razão, só começam a se desenvolver quando precedidos pelo desenvolvimento das paixões que tornam todos os seus preceitos impotentes. Fica claro assim que o chamado "pacto social", ditado pela natureza, é uma ilusão genuína... (ROUSSEAU, 2003, p. 116).

Não há, portanto, para Rousseau, uma "sociedade natural ou geral entre os homens" (ROUSSEAU, 2003, p. 120). Pode ter havido um momento em que a natureza fez e manteve os homens iguais (uniformes até), mas certamente ela não incluiu neles a

\footnotetext{
13 Derathé lembra que o título primitivo desse capítulo era "Du droit naturel et de la societé générale", o que indica muito bem a relação entre esse capítulo e o artigo de Diderot. (Pléiade, III, p. 1410). O último título ficou "De la societé générale du genre humain", traduzido em português na edição que uso como "Sobre a sociedade em geral instituída pela espécie humana”, em Rousseau e as Relações Internacionais; prefácio: Gelson Fonseca Jr. São Paulo: Imprensa Oficial do Estado, 2003.
} 
sociabilidade. Embora a humanidade seja "uma" só, ela não é naturalmente "una" (unida, unificada). ${ }^{14}$

Talvez tenha ocorrido a Diderot um raciocínio similar àquele que enunciamos no início deste trabalho, a saber: sendo a terra habitada por seres que, a despeito de apresentarem várias peculiaridades, compartilham, sem exceção, a humanidade, uma "identidade natural"; sendo os homens os únicos animais racionais que povoam o planeta, os únicos que, por causa mesmo dessa racionalidade, são capazes de comunicação e de, portanto, fazer assembleias - motivo pelo qual Diderot afirma não defender a causa do direito natural diante da animalidade, mas da humanidade (DIDEROT, 2006, p. 80) -; logo, deverá haver um interesse que seja comum (uma vontade geral) a toda a espécie humana e que dependa de um mecanismo exclusivo dessa espécie, isto é, a razão.

A identidade natural, contudo, não gera unidade entre os homens. $O$ efeito dela, segundo Rousseau, para "os vínculos iniciais da sociedade em geral" é nulo (2003, p. 114). De acordo com Derathé, no livro IV do Emílio, Rousseau mostra que "l'identité de la nature devient un sujet d'union grâce au sentimento de la commisération" (1964, p. 1411). No trecho ao qual o comentador se refere se lê: "Se nossas necessidades comuns nos unem por interesse, nossas misérias comuns nos unem por afeição" (ROUSSEAU, 2004, p. 301) ${ }^{15}$. Esta leitura está correta, já que o homem precisa se identificar com o sofredor para poder sentir-se mal com seu sofrimento. Porém, no estado natural, onde os homens são idênticos, suas forças individuais dadas pela natureza ainda superam suas necessidades, que também são naturais. Tudo de que precisa está ao seu alcance. "Sendo o corpo o único instrumento que o homem selvagem conhece", tem ele a vantagem "de sempre estar pronto para qualquer eventualidade e de transportar-se, por assim dizer, sempre todo inteiro consigo mesmo" (ROUSSEAU, 1999, p. 59) ${ }^{16}$. Sabemos que, a princípio, necessidades e miséria não são problemas para o homem natural de Rousseau. Com efeito, quando as necessidades aumentam (e se demanda a assistência dos outros), a "identidade natural" já diminui. É interessante notar como o maior grau de uniformidade entre os homens é também o menor grau de unidade entre eles, pois "a terra seria coberta de homens que quase não poderiam comunicar-se. Haveria semelhanças entre eles, mas nenhuma os uniria" (ROUSSEAU, 2003, p. 115). Eles são todos iguais antes que muitos fatores entrem em cena e comecem um processo de distinção que se perpetua. Os climas, eventos naturais, as primeiras associações, a propriedade, famílias e línguas - enfim, a "sucessão do tempo e das coisas [...], as circunstâncias e seus progressos" (ROUSSEAU, 1999, p. 43) - colocaram em movimento uma série de faculdades que os homens traziam apenas virtualmente, em stand-by, por assim dizer, e os transformaram de tal forma que eles se tornaram diferentes não só do homem primitivo, como também entre si mesmos.

\footnotetext{
14 "Quaisquer que sejam tais origens [da sociedade e das línguas], vê-se, pelo menos, o pouco cuidado que teve a natureza ao reunir os homens por meio de necessidades mútuas e ao facilitar-lhes o uso da palavra, como preparou mal sua sociabilidade e como pôs pouco de si mesma em tudo que fizeram para estabelecer os seus laços" (ROUSSEAU, 1999, p. 74)

15 Grifo nosso.

16 "E até que ponto poderiam aperfeiçoar-se e esclarecer-se mutuamente homens que, não tendo domicílio fixo nem necessidade uns dos outros, se encontrariam, talvez, somente duas vezes na vida, sem se conhecer e sem se falar?" (ROUSSEAU, 1999, p. 68). Grifo nosso.
} 
À medida que se socializaram, os homens foram perdendo sua simplicidade e uniformidade para adquirirem novas maneiras de viver. A multiplicação dos trabalhos, a diferença das terras, climas e estações, a diversidade de hábitos, de educações e "gêneros de vida que reina nas várias ordens do estado civil" (dentre outros fatores), fizeram com que o gênero humano se fragmentasse em particularizações (ROUSSEAU, 1999, pp. 82 e 88). ${ }^{17}$ Uma das primeiras consequências da formação das sociedades é a perda da uniformidade e o enfraquecimento da ideia de humanidade. E se Rousseau, no Manuscrito de Genebra, afirma que "le progrés de la societé étouffe l'humanité dans les coeurs" (1964, p. 284), é porque o interesse pessoal fará esses corações preferirem a família ao resto da nação e a nação ao resto do mundo. Não dizemos que o progresso da sociedade sufoca ou enfraquece a ligação entre os homens porque sabemos que estes - enquanto dispersos no estado de natureza (ou seja, antes daquele progresso) - já não desfrutam de qualquer ligação duradoura uns com os outros, mas porque, com o tempo, os indivíduos se ligam cada vez mais formando grupos, e estes grupos - começando em famílias e terminando (pelo menos para Rousseau) em nações -, por seu turno, se distanciam cada vez mais uns dos outros e se particularizam ${ }^{18}$

Outro ponto de discordância entre Rousseau e Diderot, cuja abordagem vem a calhar para nosso estudo, é o destaque que este último dá à razão na realização do ideal de humanidade, isto é, no resgate dos "inimigos do gênero humano" para o seio do direito natural. Para Diderot, o mau e injusto é "dominado por paixões" (DIDEROT, 2006, p. 78); o bom e justo é, consequentemente, dominado pela razão. Como já vimos, o homem participa da dignidade humana apenas se não renunciar ao seu caráter racional (DIDEROT, 2006, pp. 80 e 82). Rousseau, por outro lado, dirá no fragmento $O$ estado de guerra nascido do estado social: "Se o direito natural só estivesse inscrito na razão humana, não poderia guiar a maioria das nossas ações. Mas ele está gravado também, de forma indelével, no coração humano, e aí ele fala ao homem com mais força do que todos os preceitos da filosofia" (ROUSSEAU, 2003, p. 48). A distância entre os dois filósofos, nesse ponto, parece enorme. Enquanto um diz que "aquele que não quer raciocinar [...] deve ser tratado como um ser desnaturado" (DIDEROT, 2006, p. 82), o outro afirma que o "o homem que medita é um animal depravado" (ROUSSEAU, 1999, p. 61). ${ }^{19}$

17 Na nota $J$ ao seu Discurso sobre a origem da desigualdade, Rousseau critica os filósofos por considerarem a universalidade da espécie humana a partir da perspectiva europeia. $O$ estudo do homem partindo do europeu (assim como de qualquer outra parcela da humanidade) é eivada de confusão, pois, aos olhos de cada povo, suas particularidades aparecem como a universalidade da qual os outros povos se desviaram. O filósofo lembra que "cada um, sob o título pomposo de estudo do homem, só faz o dos homens de seu país", e que "para estudar os homens, são necessários talentos que Deus não se esforça para dar a ninguém" (ROUSSEAU, 1999, pp. 138 e 139).

18 No Ensaio sobre a origem das línguas, o autor assevera que os primeiros homens "Tinham a ideia de um pai, de um filho, de um irmão, porém não a de um homem. [...] Tanta naturalidade e tanta desumanidade; costumes tão ferozes e corações tão ternos; tanto amor pela própria família e tanta aversão pela sua espécie" (ROUSSEAU, 2000, p. 288). Já no Discurso sobre a origem da desigualdade, podemos ler: "Até então errando nos bosques, os homens, ao adquirirem situação mais fixa, aproximam-se lentamente e por fim formam, em cada região, uma nação particular" (ROUSSEAU, 1999, p. 91). Grifo nosso.

19 No Prefácio ao Discurso sobre a origem da desigualdade, no paralelo que faz entre a estátua de Glauco e a alma humana, Rousseau denuncia que "em lugar de um ser agindo sempre por princípios certos e 
Sem nos delongarmos aqui numa teoria das paixões em Rousseau e na sua crítica à razão, podemos ao menos lembrar que, longe de definir o homem, a razão é apenas uma das suas últimas aquisições, embora seja também uma das mais importantes. Além disso, ao invés de desejar silenciar paixões diante do "ato puro do entendimento", como faz Diderot, o filósofo genebrino fala em silenciá-las (a nosso ver, algumas más paixões, como o amor-próprio) diante da "voz da consciência", que, não se confundindo com a razão fria, pode mesmo ter sua fonte em sentimentos naturais como a piedade. ${ }^{20}$ Vale ressaltar que Rousseau transcreve, no capítulo II do Manuscrito de Genebra - quase que palavra por palavra -, o trecho de Diderot sobre o "silêncio das paixões", mas para refutá-lo. À solução do filósofo francês com a "volta à humanidade" por meio de sua "vontade geral" no "silêncio das paixões", Rousseau pergunta: "pode alguém pensar com objetividade sobre si mesmo?" (ROUSSEAU, 2003, p. 118). E ainda: "como a arte de generalizar ideias deste modo é um dos exercícios mais difíceis e morosos do pensamento humano, poderá o homem comum derivar desse raciocínio as regras da sua conduta pessoal?" (ROUSSEAU, 2003, p. 119). A solução de Rousseau no final do capítulo parece ser o concurso de "um espírito forte e uma mente elevada", oferecendo aos "defensores da violência" - os "inimigos da espécie humana" - novas intuições para seus entendimentos e novos sentimentos para seus corações, com os quais "terão por fim que abandonar o seu ódio, juntamente com os seus erros, [de modo que] a razão que os afasta do bom caminho os trará de volta à humanidade" (ROUSSEAU, 2003, p. 121).

De modo geral, Rousseau é assaz cético com relação ao cosmopolitismo tal qual aparece no texto de Diderot. De fato, o autor genebrino desconfia e nos aconselha a desconfiar desses "supostos cosmopolitas que, justificando seu amor pela pátria pelo amor que dedicam à espécie humana, jactam-se de amar a todos para ter o direito de não amar ninguém" (ROUSSEAU, 2003, p. 119). ${ }^{21}$ Esse ideal de humanidade é muito suspeito para ele. Na Carta ao Senhor de Franquières, por exemplo, o pensador lamenta que a "bela palavra humanidade" venha sendo "repetida agora até a insipidez, até o ridículo pelas pessoas menos humanas do mundo" (ROUSSEAU, 2005, p. 180). Porém, é bastante claro que Rousseau também

invariáveis, em lugar dessa simplicidade celeste e majestosa com a qual seu autor a tinha marcado, não se encontra senão o contraste disforme entre a paixão que crê raciocinar e o entendimento delirante" (ROUSSEAU, 1999, p. 43). Grifo nosso.

${ }^{20}$ Esse tema também é longo e dispensável para nossa tarefa, mas são pertinentes alguma alusões a ele. No final do Discurso sobre as ciências e as artes, Rousseau questiona: "E não bastará, para aprender tuas leis [da virtude], voltar-se para si mesmo e ouvir a voz da consciência no silêncio das paixões?" (ROUSSEAU, 1999, p. 214). O autor chega a tratar sobre a "consciência inata", uma consciência moral não deturpada pelas paixões. Segundo ele, "Temos um guia interior muito mais infalível do que todos os livros e que jamais nos abandona no momento da necessidade" (ROUSSEAU, 1999, p. 247). E no Emílio: “Existe, pois, no fundo das almas um princípio inato de justiça e de virtude a partir do qual, apesar de nossas próprias máximas, julgamos nossas ações e as de outrem como boas ou más, e é a esse princípio que dou o nome de consciência" (ROUSSEAU, 2004, p. 409).

21 “Desconfiai desses cosmopolitas que vão procurar longe nos livros os deveres que desdenham cumprir ao seu redor. Tal filósofo ama os tártaros para não ser obrigado a amar seus vizinhos." (ROUSSEAU, 2004, p. 11). 
utilizou esse termo, e muito. ${ }^{22}$ Uma parte extensa, interessante e extremamente importante de sua obra prende o leitor na noção que ele tem do homem para além da nação. Alguns de seus principais textos (por exemplo, os Discursos e o Emílio) são de teor mais "generalista", menos circunstancialista. O Discurso sobre as ciências e as artes promete tratar "de uma daquelas verdades que importam à felicidade do gênero humano" (ROUSSEAU, 1999, p. 183). O Discurso sobre a origem da desigualdade é endereçado ao "Homem", de "qualquer região" e "quaisquer opiniões" (ROUSSEAU, 1999, p. 53). Já Emílio (personagem do livro homônimo), não parece ser formado para ser um cidadão de um país específico, mas um homem. ${ }^{23}$

\begin{abstract}
Na ordem natural, sendo os homens todos iguais, sua vocação comum é a condição de homem, [...] a natureza o chama para a vida humana. Viver é o ofício que quero ensinar-lhe. Ao sair de minhas mãos, concordo que não será nem magistrado, nem soldado, nem padre; será homem, em primeiro lugar. (ROUSSEAU, 2004, pp. 14 e 15)
\end{abstract}

No final de seu longo período de formação, o próprio Emílio - mostrando ser uma das poucas "grandes almas cosmopolitas" 24 - garante: "Rico ou pobre, serei livre. Não o serei apenas em tal país, em tal região; sê-lo-ei por toda a terra. [...] Que me importa onde estou? Em toda parte onde há homens, estou junto a meus irmãos [...], estou em casa" (ROUSSEAU, 2004, p. 699).

Entretanto, vale frisar que, no que concerne à salvaguarda de direitos dos indivíduos, Rousseau parece atrelar sua possibilidade apenas ao seio de um corpo político determinado, com sua autoafirmação e seu conjunto coerente e singular de leis. É interessante notar que mesmo numa forma degradada de corpo político como aquela retratada no Discurso sobre a origem da desigualdade, o pacto que o institui tem como finalidade a garantia de direitos, que, nesse caso específico, se traduzem em legalização da exploração do pobre pelo rico, do fraco pelo poderoso e do escravo pelo senhor. Para que o direito não se baseasse mais na força (sempre insuficiente), os ricos refletiram e aproveitaram a ambição também dos pobres para propor: "instituamos regulamentos de justiça e de paz" (ROUSSEAU, 1999, p. 100). No Contrato Social, no capítulo "Do pacto social", Rousseau afirma que "o gênero humano, se não mudasse de modo de vida, pereceria" $\left(2000\right.$, p. 69). ${ }^{25}$ Esse novo modo de vida é a associação, que produz, "em lugar da pessoa particular de cada contratante, um corpo moral e coletivo" - um corpo político, um povo -. Porém, não se trata de um corpo do "gênero humano". Esse corpo ganha os nomes de "Estado quando passivo, soberano quando ativo, e potência quando comparado a seus

\footnotetext{
${ }^{22}$ Segundo Derathé, pautando-se em Paul Hazard, "Rousseau est, semble-t-il, le premier de nos écrivains du XVIIIe siècle à avoir employé le mot cosmopolite dans le sens d'ami du genre humain et de citoyen de l'univers" (Pléiade, v. III, p. 1414, nota 2).

${ }^{23}$ Cf. MOSCATELI, R. Por que Emílio não é o cidadão republicano. Argumentos, ano 4, nº 8, 2012.

${ }^{24}$ Cf. ROUSSEAU, 1999, p. 101. Cf. também MOSCATELI, 2012, p. 141, nota 10.

25 No entanto, o "gênero humano" não mudou o modo de vida de maneira unificada. Rousseau afirma, por exemplo, que "o estabelecimento de uma única sociedade tornou indispensável o de todas as outras" (1999, p. 100). No Emílio existe um trecho em que o autor mostra que "Ao sairmos do estado de natureza, forçamos nossos semelhantes a saírem também; ninguém pode nele permanecer apesar dos outros, e já seria realmente sair querer permanecer, dada a impossibilidade de nele viver; pois a primeira lei da natureza é o cuidado com a própria conservação" (2004, p. 258).
} 
semelhantes" (2000, p. 71). Ou seja, vista como um todo, a humanidade estará fragmentada em várias partes, cada uma delas com suas singularidades. Quando escreve para os corsos e poloneses, que procuravam constituições mais justas em seus países, Rousseau os incentiva a valorizarem suas peculiaridades, alerta para não imitarem outros povos, e aconselha para afirmarem suas identidades nacionais e promoverem, por meio da educação e outros mecanismos, o patriotismo. ${ }^{26}$

Os séculos pós Diderot e Rousseau demostraram que, no que diz respeito aos direitos humanos, não se realizaram a contento nem o ideal de humanidade (do gênero humano coeso) tampouco o ideal de nação soberana protetora de direitos. Longe de pretendermos avaliar aqui a distância entre a teoria e a prática, podemos ao menos perceber - principalmente a partir de um texto de Hannah Arendt contido em seu Origens do totalitarismo ${ }^{27}$ - como permanece forte o paradoxo do homem que, fora do Estado, não tem seus "direitos do homem" garantidos. A partir da Revolução Francesa, tão imbuída de ideias rousseauístas, ${ }^{28}$ "toda a questão dos direitos humanos foi associada à questão da emancipação nacional; somente a soberania emancipada do povo parecia capaz de assegurá-los - a soberania do povo a que o indivíduo pertencia" (ARENDT, 1989, p. 325). Porém, uma série de desdobramentos geopolíticos ${ }^{29}$ acentuaram o aparecimento de pessoas em situação de marginalização no que tange ao aparato legal e estatal. "Os apátridas", segundo Arendt, "estavam tão convencidos quanto as minorias de que a perda de direitos nacionais era idêntica à perda de direitos humanos e que a primeira levava à segunda" (1989, p. 325 e 326). Como é possível significar o mesmo perder a ligação com qualquer aparato legal e perder a ligação com a humanidade? $\mathrm{O}$ século $\mathrm{XX}$, principalmente, evidenciou que homens "fora do Estado" podem ser tratados também como "homens fora da humanidade", de tal forma que muitos refugiados (ou deslocados) tinham mais esperança de terem seus direitos reconhecidos se os exigissem "na qualidade de poloneses, judeus, alemães, etc." (ARENDT, 1989, p. $326)$, do que se os reclamassem como membros da humanidade. ${ }^{30} \mathrm{O}$ alijamento de um governo nacional próprio impossibilitava de tal maneira o usufruto de direitos humanos, que a desnacionalização viria a se tornar "poderosa arma de política totalitária" (ARENDT, 1989, p. 302). A filósofa assevera no texto:

\footnotetext{
26 “A primeira regra a seguir", sugere Rousseau aos corsos, "é a de caráter nacional. Cada povo tem, ou deve ter, um caráter nacional, e se ele não existe será preciso começar por criá-lo" (2003, p. 192). Nas Considerações sobre o governo da Polônia, o autor escreve que, "Se houver a garantia de que nenhum polonês jamais se transformará em russo, garanto que a Rússia não poderá subjugar a Polônia" (2003, p. 230).

${ }^{27}$ Trata-se do capítulo 5 da segunda parte (Imperialismo), intitulado “O declínio do Estado-nação e o fim dos direitos do homem".

${ }^{28}$ Como, por exemplo, a de que o homem seria a fonte da lei, de que a sociedade não conteria camadas privilegiadas, e de que a Vontade Geral do corpo político soberano salvaguardaria o bem de seus membros.

${ }^{29}$ Como, por exemplo, o imperialismo, a formação e fortalecimento dos Estados nacionais, os Estados multinacionais, revoluções, ditaduras, guerras civis e as duas Grandes Guerras Mundiais.

30 "O mundo não viu nada de sagrado na abstrata nudez de ser unicamente humano" (ARENDT, 1989, p. 333). E “O paradoxo da perda dos direitos humanos é que essa perda coincide com o instante em que a pessoa se torna um ser humano em geral" (ARENDT, 1989, pp. 335 e 336).
} 
Os Direitos do Homem, afinal, haviam sido definidos como "inalienáveis" porque se supunha serem independentes de todos os governos; mas sucedia que, no momento em que seres humanos deixavam de ter um governo próprio, não restava nenhuma autoridade para protegê-los e nenhuma instituição disposta a garanti-los. (ARENDT, 1989, p. 325).

Este trecho de Arendt retoma bem a discussão que fazíamos acerca daquelas Declarações de Direitos do Homem do século XVIII. As próprias Declarações principiam por definir os direitos como "inalienáveis" do homem em geral, mas terminam por ligá-los inexoravelmente a algum aparato jurídico-estatal. As duas primeiras Declarações, as de 1776 (EUA) e 1789 (França), como explica Norberto Bobbio, ${ }^{31}$ têm ponto de partida "universal", mas ponto de chegada "particular". Elas anunciam a universalidade natural dos direitos do homem, mas se "positivam" apenas na nação. Elas são, por assim dizer, a princípio diderotianas e por fim rousseauístas. No entanto, a Declaração de 1948 aponta para um processo de universalização e positivação, no final do qual "os direitos do cidadão terão se transformado, realmente, positivamente, em direitos do homem" (BOBBIO, 2004, p. 30). Se apenas os cidadãos têm direitos, todos os homens os terão quando houver uma espécie de "cidadania do mundo". ${ }^{32}$

Esta "cidadania do mundo" surge com maior expressividade em dois pequenos textos de Kant ${ }^{33}$ e na Declaração Universal dos Direitos Humanos, de 1948, que juntos parecem ser um avanço na discussão do problema que nos propomos aqui. Por isso, podemos terminá-la procurando estabelecer uma ponte entre Kant e Rousseau com o objetivo de identificar que, em certa medida, a segurança que a ordem política e jurídica do Corpo Político rousseauísta representa para o cidadão, um "corpo de todos os homens" (um "Estado dos povos" 34 ) - que tenha ordem política, jurídica e policial - representa para o homem. Além disso, parece-nos sobremodo significativo que, para além da "Declaração dos direitos do homem americano" contra a coroa inglesa e da "Declaração dos direitos do homem francês" contra o Antigo Regime, a Declaração Universal dos Direitos Humanos se levante contra a guerra, pois, como "fundamento da liberdade, da justiça e da paz no mundo" ela aponta "o reconhecimento da dignidade inerente a todos os membros da família humana", além de pregar ser "essencial promover o desenvolvimento de relações amistosas entre as nações" (HUNT, 2009, p. 229). ${ }^{35}$ Daí a importância de conhecermos um pouco o pensamento do filósofo alemão a esse respeito, mesmo que seja a partir de textos escritos cerca de 150 anos antes desta Declaração.

A tese de Kant (que se encontra de certa forma nos dois textos e segue, no plano das nações, o que os contratualistas mostravam no plano dos indivíduos) é que, assim como os homens saíram do estado de natureza para o seu próprio bem, os

${ }^{31} \mathrm{Em}$ A Era dos Direitos, no capítulo intitulado "Presente e futuro dos direitos do homem".

32 "Somos tentados a descrever o processo de desenvolvimento que culmina da Declaração Universal também de um outro modo, servindo-nos das categorias tradicionais do direito natural e do direito positivo: os direitos do homem nascem como direitos naturais universais, desenvolvem-se como direitos positivos particulares, para finalmente encontrarem sua plena realização como direitos positivos universais" (BOBBIO, 2004, p. 30).

33 A saber: Ideia de uma história universal de um ponto de vista cosmopolita è À paz perpétua.

${ }^{34}$ Civitas gentium (KANT, 2008, p. 36).

${ }^{35}$ Grifo nosso. 
Estados farão, com o tempo, o mesmo movimento com a mesma finalidade. Se, por um lado, o desenvolvimento dos Estados-nações soberanos, com seu arcabouço jurídico, representa teoricamente melhor proteção aos direitos civis e sociais dos cidadãos, por outro, porém, acentua um dado que Rousseau e, depois, Kant repetem: ${ }^{36}$ os indivíduos constituem o Estado esperando evitar os problemas que se causavam mutuamente no estado natural, mas os próprios Estados constituídos permanecem em estado de natureza, suscetíveis aos mesmos problemas que os particulares enfrentavam antes. Tanto em Rousseau como em Kant, uma vez instituídas as sociedades, persistirá entre elas um estado de natureza. Enquanto o autor genebrino afirma que os corpos políticos, nessa condição, "logo se ressentiram dos inconvenientes que haviam forçado os particulares a sair dele" (ROUSSEAU, 1999, p. 101), o alemão diz que os povos, "como Estados, podem ser considerados como homens individuais que, em seu estado de natureza [...] já se lesam por estarem um ao lado do outro" (KANT, 2008, p. 31).

Em seu Ideia de uma história universal, Kant observa a história com uma noção de progresso, de um processo lento e - aos olhos dos particulares aparentemente incompreensível (oculto, irrefletido, inconsciente) que vai da extrema barbárie, violência e individualismo à completa realização do objetivo da natureza num corpo político formado por todos os homens seguindo leis comuns. De acordo com o autor, o propósito supremo da natureza é "um Estado cosmopolita universal, como o seio no qual podem se desenvolver todas as disposições originais da espécie humana" (KANT, 2011, p. 19). Todavia, o maior propósito é também o maior problema, pois "alcançar uma sociedade civil que administre universalmente o direito" (KANT, 2011, p. 10) "depende do problema da relação externa legal entre Estados" (KANT, 2011, p. 12). Curiosamente, ao invés de unir os homens utilizandose da razão ou sentimentos que estes possuam, é por meio da "insociável sociabilidade" (KANT, 2011, p. 8), do antagonismo, que a natureza realizará seu projeto. "Toda cultura e toda arte que ornamentam a humanidade, a mais bela ordem social são frutos da insociabilidade" (KANT, 2011, p. 11). ${ }^{37}$

Na relação entre Estados, como na relação entre indivíduos, esse antagonismo se traduz em estado de guerra. Lembrando o verbete de Diderot e o comentário de Rousseau, cada sociedade seria, com relação às outras, uma espécie de "raciocinador violento" que não vê garantia de que as outras não o sejam também, e faz tudo egoistamente, mesmo que isso possa significar a ruína de quase todo o resto

\footnotetext{
${ }^{36} \mathrm{O}$ primeiro para atestar a dificuldade do Projeto do Abade de Saint-Pierre (ROUSSEAU, 2003, pp. 77 e 100) e o segundo para propor seu próprio "projeto".

$37 \mathrm{Em}$ seu $\grave{A}$ paz perpétua, Kant afirma que a primeira garantia para essa paz é "a grande artista natureza, em cujo curso mecânico transparece visivelmente a finalidade de fazer prosperar a concórdia pela discórdia dos homens, mesmo contra sua vontade" (2008, p. 42). É interessante observar o lugar do antagonismo no projeto da natureza com vista à paz. Depois de anunciar, como "Primeiro artigo definitivo para a paz perpétua", que "A constituição civil em cada Estado deve ser republicana" (2008, p. 24), o autor diz que esta não é constituída por um povo de "anjos", mas de "demônios" (2008, p. 50), pois, se não houver conflitos não há razão para o direito. Os antagonismos, a guerra, unidos à consciência de que a paz é melhor, levam ao estabelecimento de normas para gerir as relações e dirimir as lutas.
} 
(DIDEROT, 2006, p. 79). ${ }^{38}$ Como Hobbes bem o demonstrou ${ }^{39}$ (e outros contratualistas de certo modo o repetiram), aqueles que são afetados por esta condição conflituosa e insustentável deverão procurar uma saída para ela em direção à paz e segurança. Segundo Kant,

\begin{abstract}
Assim como olhamos com profundo desprezo o apego dos selvagens à sua liberdade sem lei de preferir brigar incessantemente a submeter-se a uma coerção legal a ser constituída por eles mesmos, por conseguinte preferindo a liberdade insensata à racional, e os consideramos estado bruto, grosseria e degradação animalesca da humanidade, deveríamos pensar que povos civilizados (cada um unido em um Estado) teriam de apressar-se a sair o quanto antes de um estado tão abjeto (2008, pp. 31 e 32$).{ }^{40}$
\end{abstract}

Portanto, para chegarem à paz perpétua entre as nações e ao bem dos homens, os Estados precisarão, com o tempo, abrir mão das "atrocidades do emprego da força" (tão característico do estado natural de guerra), consentir "a leis públicas de coerção" e formar um "Estado de povos (civitas gentium), que por fim viria a comprometer todos os povos da Terra" (KANT, 2008, p. 36).

Porque o direito natural, segundo Kant, faz da Terra um lugar de todos (2008, p. 38), ele tende a levar estes habitantes a um pacto social parecido, em certo sentido, com o de Hobbes (no nível dos indivíduos) devido ao estado permanente de guerra entre todos os Estados. Em outros sentidos, porém, esse acordo dos povos na instituição de um Estado cosmopolita parece-se com o que Rousseau sugere para uma sociedade (também de particulares) bem ordenada, que resulta numa "associação que defenda e proteja a pessoa e os bens de cada associado com toda a força comum", onde cada um se submete à vontade do Corpo Político do qual é membro e permanece, por isso, livre obedecendo a si mesmo (ROUSSEAU, 2000, Livro I, cap. VI) na medida em que participa da elaboração das leis. Kant, por sua vez, afirma que

a natureza impele [os Estados a] sair do estado sem leis dos selvagens para entrar numa federação de nações em que todo Estado, mesmo o menor deles, pudesse esperar sua segurança e direito não da própria força ou do próprio juízo legal, mas somente desta grande confederação de nações de um poder unificado e da decisão segundo leis de uma vontade unificada $\left(2011\right.$, p. 13). ${ }^{41}$

38 Rousseau afirma, no capítulo II do Manuscrito de Genebra, que a prova de plausibilidade do raciocínio desse vilão (l'homme éclairé et indépendant) de Diderot é que "assim pensa qualquer sociedade soberana responsável pela sua conduta somente perante si mesma” (2003, p. 117).

${ }^{39}$ Cf. capítulos 13 e 17 do Leviatã.

${ }^{40}$ Em um trecho com o mesmo teor, só que no Ideia de uma história universal, lê-se: “A mesma insociabilidade que obrigou os homens a esta tarefa é novamente a causa de que cada república, em suas relações externas [...] esteja numa liberdade irrestrita, e consequentemente deva esperar do outro os mesmos males que oprimiam os indivíduos e os obrigavam a entrar num estado civil conforme leis" (2011, p. 13).

${ }^{41}$ Além do que vimos no trecho do Contrato Social, é interessante notarmos que Rousseau expressa algumas considerações sobre a federação de Estados no Extrato e Julgamento do Projeto de paz perpétua com as quais as de Kant vão se assemelhar. Cf. ROUSSEAU, 2003, pp. 89 e 94. 
Um pouco à frente, o filósofo alemão assevera que os Estados imitarão a "decisão que coagiu tão a contragosto o homem selvagem, a saber: abdicar de sua liberdade brutal e buscar tranquilidade e segurança numa constituição conforme leis" (2011, pp. 13 e 14). Ora, essa federação de nações que nasce daí conduzirá gradualmente todos os Estados à paz perpétua (KANT, 2008, p. 35) e não será hobbesiana a ponto de se configurar numa "monarquia universal" (KANT, 2008, p. 52), mas numa república nos moldes rousseauístas, em que cada membro conservará a liberdade ${ }^{42}$ no consentimento a leis comuns (KANT, 2008, p. 36), pois o “direito internacional deve fundar-se em um federalismo de Estados livres" (KANT, 2008, p. 31). ${ }^{43}$

Pelo que expomos até aqui, o Estado cosmopolita é, para Kant, a realização suprema do "direito" e da política, assim como, na nossa opinião, da possibilidade de reconhecimento e salvaguarda de direitos humanos para todos os homens. $\mathrm{E}$ isso na medida em que significa o cume de uma escalada da humanidade. No primeiro nível, a falta do aparato jurídico-estatal representa para os indivíduos uma situação de desrespeito mútuo por suas pessoas; no segundo, a não existência de uma "esfera superior às nações" (ARENDT, 1989, p. 332) e de normas compartilhadas pelos povos empurra uma parcela significativa dos homens a condições degradantes e a uma constante ameaça de guerras, com a suspensão de direitos civis e sociais até mesmo dos cidadãos. O Estado cosmopolita, essa república de nações, onde a condição de cidadania alcança todo homem, é o terceiro e último nível, em que, segundo o pensador alemão, a natureza completará seu propósito para a espécie humana, usando como meio o conflito, mas tendo sempre a paz como finalidade.

Portanto, para nos considerarmos portadores de direitos humanos, não basta $^{44}$ o simples fato de sermos todos humanos, com características que nos distinguem de todo o resto do mundo e nos "aproxima" - melhor, nos uniformiza - a todos. ${ }^{45}$ Também não parece bastar, embora seja um avanço, levantar uma espécie

\footnotetext{
42 Apesar de parecer tão hobbesiano na descrição do estado de guerra em que se encontram os Estados (quando estes tem uma liberdade selvagem [sem lei]), quando, porém, trata da liberdade jurídica (ver nota de Kant à "constituição republicana" no "Primeiro artigo definitivo para a paz perpétua", p. 25), Kant parece assumir a noção rousseauísta da liberdade na obediência à lei que eu mesmo faço e se distancia da noção hobbesiana da liberdade na ausência de impedimento externo (permissão) à minha vontade.

${ }^{43}$ No Tratado sobre a economia política, Rousseau, quando compara a "economia pública popular" à "economia pública tirânica", termina o parágrafo dizendo que as regras da primeira seriam encontradas apenas "nas obras dos filósofos que se dispõem a proclamar os direitos da humanidade" (2003, p. 10, grifo nosso). Na nota "a" ao Discurso sobre a desigualdade, o autor afirmará que "os poderosos temem mais do que a morte uma espécie de governo [o republicano] que os force a respeitar os homens" (1999, p. 119). Kant, de sua parte, observará que, para haver paz, a constituição deve ser republicana, pois nesta não são os poderosos que decidem sobre a guerra, mas o "consentimento dos cidadãos" (2008, p. 26).

${ }^{44}$ Como em Diderot.

45 A razão do gênero humano em Diderot é diferente da razão que domina a história em Kant. O autor francês supõe uma ligação entre os homens a partir de uma razão exclusiva que os distingue dos animais e que caracteriza sua dignidade e os une no respeito se conseguir silenciar as paixões. Já no pensador alemão, a razão parece uma "razão da natureza" (da História), que influencia (rege) tanto os animais quanto os seres humanos. A segunda proposição do Ideia de uma história universal, nos faz entender que os esforços da sábia natureza não correm o risco de, só por causa do homem, serem um "jogo infantil" (2011, p. 6). Se em todo o resto a natureza demonstra sua sabedoria, o que nos faria escapar dela?
} 
de tenda ${ }^{46}$ que proteja a todos que estiverem abrigados, mas que não abrigue a todos. Com o que pensa Kant e pretende a Declaração Universal dos Direitos Humanos de 1948, vislumbra-se a possibilidade da "família humana" inteira, em cada canto de sua "grande casa", ser acolhida pelo direito. Percebe-se assim que não é pelo indivíduo, ou pela espécie, mas pela política e seu arcabouço jurídico-estatal que se pode ter alguma esperança de efetivação dos direitos do homem. Se a política é o que resguardava esses direitos, nas Declarações do século XVIII (e seus fundamentos filosóficos), apenas no plano das nações, pretende-se, na Declaração do século XX (e em Kant), que a política ampare todos os homens.

Mesmo que ultrapasse nosso objetivo, nesse trabalho filosófico, nos perguntar sobre uma implicação necessária entre o "vislumbre de possibilidade" e a efetiva realização da paz entre as nações e dos direitos humanos, podemos ao menos concluir defendendo que - primeiro com Kant - a paz perpétua "não é uma ideia vazia, mas uma tarefa" (2008, p. 85) e, - depois com Rousseau ${ }^{47}$ - "se a despeito de tudo isso o projeto não for executado, não o será por utópico, mas pela loucura dos homens" (2003, p. 100). Negligenciando essa tarefa, a loucura dos homens pode direcionar a história para um desfecho bem diferente daquele que Kant imagina, levando-a a um ponto que, curiosamente, o próprio autor conjeturou (2008, p. 20): “encontraria a paz perpétua somente no grande cemitério do gênero humano".

${ }^{46}$ Como em Rousseau, os Estados-nações e as Declarações do século XVIII.

${ }^{47}$ Embora se referindo ao Projeto do Abade de Saint-Pierre, cabe bem aqui. 


\section{Referências bibliográficas}

ARENDT, Hannah. Origens do totalitarismo. São Paulo: Cia das letras, 1989.

BOBBIO, Norberto. A era dos direitos. Rio de Janeiro: Elsevier, 2004.

DIDEROT, Denis. Direito Natural. In: Verbetes políticos da enciclopédia. Trad. Maria das Graças de Souza. São Paulo: Discurso Editorial; Editora Unesp, 2006.

HOBBES, Thomas. Leviatã ou matéria, forma e poder de um Estado eclesiástico e civil. São Paulo: Nova Cultural,1997.

HUNT, Lynn. A invenção dos direitos humanos: uma história. São Paulo: Cia das Letras, 2009.

KANT, Immanuel. À paz perpétua. Trad. Marco Zingano. Porto Alegre: L\&PM, 2008 .

. Ideia de uma história universal de um ponto de vista cosmopolita. Trad.

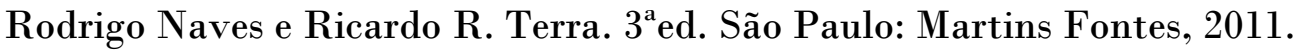

LOCKE, John. Segundo tratado sobre o governo. Trad. Anoar Aiex e Jacy Monteiro, 2 ed. São Paulo: Abril Cultural, 1978. (Col. Os Pensadores).

MOSCATELI, Renato. Por que Emílio não é o cidadão republicano. In: Argumentos, ano $4, \mathbf{n}^{\circ} 8,2012$.

ROUSSEAU, Jean-Jacques. Carta a Christophe de Beaumont e outros escritos sobre a religião e a moral. Trad. José Oscar de Almeida Marques. São Paulo: Estação Liberdade, 2005.

Discurso sobre a origem e os fundamentos da desigualdade entre os homens. São Paulo: Nova Cultural, 1999. (Col. Os Pensadores II).

Discurso sobre as ciências e as artes. São Paulo: Nova Cultural, 1999. (Col.

Os Pensadores II). Do contrato social. São Paulo: Nova Cultural, 2000. (Col. Os Pensadores I). . Emílio ou da educação. Trad. Roberto Leal Ferreira, 3 ed. São Paulo: Martins Fontes, 2004. (Paidéia)

. Rousseau e as Relações Internacionais; prefácio: Gelson Fonseca Jr. São Paulo: Imprensa Oficial do Estado, 2003.

. Oeuvres Complètes. Paris: Gallimard, 1964. v.3 (Bibliothèque de la Plêiade).

Autor(a) para correspondência: Moisés Rodrigues da Silva, Instituto Federal de Goiás - Campus Itumbiara, Av. Furnas, 360, Village Imperial, CEP 75524-360, Itumbiara - GO, Brasil. professormoisesrodrigues@hotmail.com 